\title{
HIGHLIGHTS OF ASTRONOMY
}

\author{
VOLUME 6
}

\author{
Edited by
}

\author{
RICHARD M. WEST
}

\begin{abstract}
Many hundreds of talks were delivered at the XVIIIth IAU General Assembly in Patras, Greece, 17 - 26 August, 1982 and this book brings together about 100 of these. Four invited discourses were given by distinguished scientists: 'Astronomy in Ancient Greece': M. A. Hoskin; 'The Origin and Early History of the Sun and the Planetary System': G. A. Herbig; 'Modern Cosmology': Ya. B. Zeldovich; and 'Recent Research on Solar Flares': C. de Jager. Together with these four talks, the present volume contains the proceedings of six Joint Discussions, i.e. 'Mini-Symposia' arranged by several commissions and each lasting an entire day. They center on broad subjects of great actuality and review, in a compact way, the status of research in a particular field of astronomy. Of the many Joint Commission Meetings held in Patras, seven have been selected for inclusion here. They are, in most cases, concerned with more specialized subjects than are the Joint Discussions, but they similarly summarize the latest information within the given subject field.
\end{abstract}

